\title{
Noise Reduction in Pavement Made of Rubberized Bituminous Top Layer
}

\author{
Fotini Kehagia1, Sofia Mavridou ${ }^{2}$ \\ ${ }^{1}$ Laboratory of Highway, Department of Civil Engineering, Aristotle University of Thessaloniki, Thessaloniki, Greece \\ ${ }^{2}$ Laboratory of Building Materials, Department of Civil Engineering, Aristotle University of Thessaloniki, \\ Thessaloniki, Greece \\ Email: fkehagia@civil.auth.gr, smavrido@civil.auth.gr
}

Received 30 June 2014; revised 2 August 2014; accepted 15 August 2014

Copyright (C) 2014 by authors and Scientific Research Publishing Inc.

This work is licensed under the Creative Commons Attribution International License (CC BY).

http://creativecommons.org/licenses/by/4.0/

(c) (i) Open Access

\begin{abstract}
In Greece more than 60,000 tn End of Life Tires are stockpiled every year often uncontrollable, causing severe environmental and other socio-economic negative impacts. Studies up to date are focused mainly on mechanical and physical characteristics of rubberized mixtures (based on cement, asphalt or soil) in which tire rubber is used either as alternative to natural aggregates or as additive. However, effect of tire rubber on noise reduction in rubberized bituminous layers, which is the main topic of present paper, has not been widely studied. In particular, this research paper is dealing with a sustainable use of tire rubber in asphalt pavement, leading to its generated noise reduction. An experimental pilot application has been conducted in the frame of a European Research Project, which has been implemented in a heavy traffic road section, cited outside Lamia city of Greece, (Vasilikon Street). The upper surface layer of the pavement has been made of rubberized bituminous mixture, produced by the wet process. Rheological characteristics of rubberized bitumen as well as basic properties of the implemented, rubberized bituminous mixture are presented. Moreover, measurements of noise level, deriving from vehicles' motion, under operational conditions took place at the road section right after its implementation as well as after 8 months of its operation, while all data are presented in details. Results of the measurements on conventional and modified pavement sections are compared, certifying that rubberized asphalt layers can be not only environmentally friendly-since a category of solid wastes (worn automobile tires) is utilized-but also, addition of tire rubber particles in bituminous binder provides up to $3 \mathrm{~dB}$ noise reducing bituminous mixtures and pavements, noise reduction that remains even after 8 months of road section's operation.
\end{abstract}

\section{Keywords}

End of Life-Tires, Rubberized Bituminous Mixtures, Noise, Pavement, Traffic, Waste Management 


\section{Introduction}

Annually, a steady stream of large volume of waste tires is generated due to the continual increase in the number of all kinds of transport vehicles. Especially for the European Community (Austria, Belgium, Denmark, Finland, France, Germany, Greece, Holland, Ireland, Italy, Luxembourg, Portugal, Spain, Sweden, UK), this amount is estimated at up to 250 million waste tires, while equal amounts are estimated for East Europe, North and Latin America, Japan and Middle-East. In addition to this, 3 billion of EOL Tires have already been stockpiled or land filled inside the EC and almost 1 billion in North America [1]. In Greece, the annual deposit of worn mobile tires comes up to 58,500 - 70,000 t, causing a major environmental problem.

Because of the increase in the number of tires accumulating around the world and environmental hazards associated with them, more nations are looking for ways to make use of this waste product. Tire rubber can be used in various civil engineering applications, such as for the production of pastes, mortars and concrete based on cement [2]-[4], based on bituminous binder [5]-[7] or soil [8]. Studies so far, show that utilization of recycled rubber from worn mobile tires in the road construction sector can be a very promising and environmentally friendly way to eliminate the nations' stock of scrap tires.

Rubberized asphalt is a process of incorporating fine crumb rubber particles with asphalt paving materials. The processes of applying crumb rubber from tire waste in bituminous mixtures can be divided into two categories: the dry process and the wet process. In the dry process, crumb rubber is added to the aggregates before introducing the asphalt binder to the mixture, i.e. crumb rubber acts as a partial replacement to some of the aggregate sizes. In the wet process, bituminous binder is pre-blended with tire rubber at high temperature $\left(150^{\circ} \mathrm{C}\right.$ $210^{\circ} \mathrm{C}$ ) and under specific blending conditions. Crumb rubber particles in the dry process are normally coarser than those in the wet one because they are considered as part of the aggregate gradations. Whereas, in wet process, fine crumb rubber powders fully react with bituminous binders and improve the binder properties [6]. In Greece, the use of rubber in asphalt pavements is still a nationally relatively unexplored area with manyaccording to worldwide literature_-advantages. This "new” product remains under-utilized mostly due to lack of knowledge of the technical world.

Rubberized asphalt provides a safer, smoother and quieter road surface. The main theme of this paper is the effectiveness of rubberized asphalt as traffic noise mitigation measure. In the frame of LIFE+ project with Acronym ROADTIRE (Integration of end-of-life tires in the life cycle of road construction), co-funded by the European Commission, a pilot project of the design and construction of rubberized asphalt pavement has been conducted, after extensive laboratory research. A road section in the city of Lamia in the region of Sterea Ellada-Vasilikon street, was selected for the pilot application. The upper bituminous layer of the pavement has been made of rubberized bituminous mixture produced by the wet process and its basic properties are presented. However, present paper focuses on data concerning traffic noise level during various time periods of a day and theirs' comparison on conventional pavements and rubberized one of Vasilikon street, which is characterized by heavy traffic.

\section{Material and Methods}

\subsection{Participants}

In the frame of LIFE+ project with Acronym ROADTIRE (Integration of end-of-life tires in the life cycle of road construction), co-funded by the European Commission, a pilot project of the design and construction of rubberized asphalt pavement has been conducted, after extensive laboratory research. A road section in the city of Lamia in the region of Sterea Ellada-Vasilikon street, was selected for the pilot application. The upper bituminous layer of the pavement has been made of rubberized bituminous mixture produced by the wet process and its basic properties are presented. However, present paper focuses on data concerning traffic noise level during various time periods of a day and theirs' comparison on conventional pavements and rubberized one of Vasilikon street, which is characterized by heavy traffic.

\subsection{Materials}

Rubberized asphalt is composed of asphalt/bituminous binder, in which tire rubber is added at various percentages, in order to obtain a uniform final product, which is called the rubberized asphalt. This new product requires higher mixing temperatures compared to the conventional one, as well as increased mixing time [9]. Pre- 
liminary mix design should aim at rubberized binders with:

1) Relatively low viscosity, so as to compact easily.

2) Elasticity as common elastomer binder.

3) Penetration and R\&B (Ring \& Ball) test similar to the common elastomeric binder.

4) To be as homogeneous as possible (which means very fine rubber particles included).

Moreover, rubber particles should have high specific surface, while time and temperature of mixing during production should be technically reasonable (acceptable from binder's production units).

In the frame of this research, various series of rubberized asphalt-with and without additives-have been produced and examined in the lab. All procedures have taken place at the Department of Materials Testing and Control of Quality of Public Works of Sterea Ellada in cooperation with Laboratory of Building Materials, of the Department of Civil Engineering of Aristotle University of Thessaloniki.

Mixing temperature for all binders (conventional and rubberized ones) ranged from $150^{\circ} \mathrm{C}-210^{\circ} \mathrm{C}$ depending on the percentage of tire rubber included, while mixing time was kept constant at 2 hours. Properties examined included: penetration, softening point (ring and ball test), viscosity, elastic recovery, ductility and stereoscopic examination, while all tests have been conducted according to existing test/control standards. Taking into account all the rheological characteristics examined, the composition which behaved best to all properties and which has been further suggested for the pilot application was the special modified rubberized binder with the addition of tire rubber at $10 \%$ wt. This binder is produced under special designed and controlled production conditions. In particular, the special process ensures maximum possible swelling and dispersion of tire rubber into the bitumen, in order to have a final binder with high elastomeric properties and high softening point. Bitumen is mixed with tire rubber powder, into special designed high shear mixers at ( 1000 rpm) for 2 hours, at a temperature of $\leq 180^{\circ} \mathrm{C}-185^{\circ} \mathrm{C}$ in order to avoid fumes. Successful mixing in such temperature values can be accomplished with the addition of a small percentage of special additive/s $\sim$ suggested percentage $3 \% \mathrm{w} / \mathrm{t}$ - that are reducing the mix viscosity. After mixing time, the product is passing through a colloid mill of $\sim 3000$ rpm in order to ensure further dispersion of the tire rubber powder. High shear mixers are vertical cylindrical vessels of 15 cubic meters capacity, having a high speed revolving screw type axis, able to spin with $1000 \mathrm{rpm}$ at full capacity, with a liquid of more than 10.000 cPs viscosity [10].

Parallel to mixing, the blend can be recirculated internally, through a homogenizer colloid mill in order to obtain the maximum dispersion of the crumb rubber on the one hand, while on the other, possible bigger particles of rubber can be reduced in size, promoting this way the better reaction of rubber with bitumen. With these mixing facilities, one can obtain both maximum interaction of rubber with bitumen, and take advantage of its elastic properties. Conventional mixing will only entrap the crumb rubber into the bituminous binder and the crumb rubber will act only as filler into the asphalt mix. The colloid mill is of the same design as the ones used for the bituminous emulsions production. It consists of a disk stator, equipped with metal teeth, and a high speed rotor (3000 rpm) with the same teeth type, having a gap of only 10 microns as they pass through the teeth of the stator. The blend is forced to recirculate through these teeth, ensuring fast and maximum reaction, as well as, minimum size of crumb rubber in presence. After approximately 2 hours, viscosity of the blend rises, since reaction finishes. High viscosities can create compaction problems afterwards, and the only way to overcome this, is by increasing compaction temperature, or by incorporating viscosity reducers of the paraffin wax type of hydrocarbons (C-10 to C-12).

For the purpose of this research, viscosity reducer additives have been used since they are more environmentally friendly, keeping this way compaction temperature at normal levels, minimizing fume exposure. Characteristics of specific binder used for the pilot application as well as of conventional one are shown on Table 1.

Table 1. Characteristics of binder used for the pilot application as well as of conventional one.

\begin{tabular}{ccc}
\hline Rheological characteristic & Value for rubberized bitumen (pilot application) & Value for conventional 50/70 \\
\hline Penetration at $25^{\circ} \mathrm{C}$, pen & 39 & 55 \\
Softening point, ${ }^{\circ} \mathrm{C}$ & 67 & 46 \\
Ductility at $25^{\circ} \mathrm{C}, \mathrm{cm}$ & 31 & 110 \\
Viscosity at $~ 1000 \mathrm{cps},{ }^{\circ} \mathrm{C}$ & 180 & 123 \\
Elastic recovery, $\%$ & $\geq 60$ & 10 \\
\hline
\end{tabular}


It must be noted that the city of Lamia in central Greece, where pilot application took place by implementing rubberized bituminous mixture, has high summer-time temperatures, considerably low winter-time temperatures, and medium to heavy traffic loads, so elasticity, elevated Softening Point and high stiffness of the modified binder, were properties highly required for the design of the mixture to be used. That way, mainly Mediterranean countries, with similar temperature and operative conditions, can use ROADTIRE's technology.

The mixture used for the pilot application has been produced by the wet process, which means that modified rubberized bitumen has been used as the bituminous binder. During this process, tire rubber particles modify the rheological characteristics of the binder, as mentioned above. This modification is attributed to physical and compositional changes due to the interaction between rubber particles and the bituminous binder. In many countries such as America and in some European ones (e.g. Italy, Spain, Germany etc.), the wet process is a very common method used to produce rubberized asphalt concrete with improved characteristics such as noise reduction and longer pavement life with reduced maintenance costs [5] [7].

Specifically, bituminous mixture used, for the pilot application in the city of Lamia, was a dense graded one containing 5\% modified bituminous binder. The produced mixture consisted of rubberized bitumen and natural aggregates. As far as the bituminous binder is concerned, it was a special one, capable of accepting modification by tire rubber particles. This binder is produced by the addition of 10\% w/t of Tire Rubber Powder $(0-1 \mathrm{~mm})$, under special designed and controlled production conditions in conventional bituminous binder 50/70. Aggregates used were of limestone origin from a quarry near the city of Lamia. As far as the bituminous mixture is concerned, it was produced and tested at the Laboratory of the Department of Material's Control and Public Works' Quality of Sterea Ellada in cooperation with Laboratory of Building Materials of the Department of Civil Engineering of Aristotle University of Thessaloniki according to European [11] and Greek [12] specifications, which are in force for conventional bituminous mixtures and for surface bituminous layer. Tests on properties of raw materials (aggregates and tire rubber) took also place at the above laboratories, while all values of properties examined complied with relevant specifications. Furthermore, rutting resistance has been examined according to ПЕТЕП 05-03-11-04 [13] based on EN 12697-22 (2003) [14] Bituminous Mixtures-Tests methods for hot mix asphalt-Part 22: Wheel tracking. The European Standard followed for this test describes test method for determining the susceptibility of bituminous materials to deform under load. Laboratory results of all tests conducted for both conventional and rubberized bituminous mixtures are shown on Table 2.

Table 2. Marshall Characteristics and rutting resistance of composition with $10 \%$ tire rubber and the addition of the special modified binder and of conventional one.

\begin{tabular}{|c|c|c|c|}
\hline \multirow{3}{*}{ Characteristic } & \multicolumn{3}{|c|}{ Binder's content $5 \%$} \\
\hline & \multirow{2}{*}{ Value for rubberized } & \multirow{2}{*}{ Value for conventional } & Limit according to \\
\hline & & & ПТП ${ }^{\mathrm{a}}-265$ A (standard)-Heavy traffic \\
\hline Compaction (No) & 75 & 75 & \\
\hline Marshall stability at $60^{\circ} \mathrm{C}$ (lbs) & 3265 & 2625 & $\geq 1500$ \\
\hline Deformation at $0.01 "$ & 14.5 & 11.5 & $10-16$ \\
\hline Specific gravity & 2410 & 2375 & NA \\
\hline Voids on aggregates (\%) & 15 & 16.4 & $\geq 15$ \\
\hline \multirow[t]{2}{*}{ Voids on bituminous mixture (\%) } & 3.5 & 5 & 3 - 5 (Limit according to \\
\hline & & & ПЕТЕП' \\
\hline Rut depth (mm) & 1.6 & 2.3 & $<4 \mathrm{~mm}$ \\
\hline Rate of rutting (mm/h) & 0.84 & 1.2 & $<2 \mathrm{~mm} / \mathrm{h}$ \\
\hline
\end{tabular}

${ }^{\mathrm{a}}$ П.Т.П.: Temporary Technological Guidelines in Greece for road construction (1966); ${ }^{\mathrm{b}}$ П.Е.ТЕ.П.: Temporary National Technological Guidelines in Greece (2006). 


\subsection{Theoritical Part}

Studies conducted internationally have shown that rubberized asphalt can reduce; associated with roadway traffic, noise pollution. This phenomenon was first noted in Belgium, in 1981, where studies on asphalt rubber hot mix showed a dramatic reduction in noise levels. As a result, countries around the world have started noise level studies in order to evaluate the validity of claims being made. The Federal Highway Administration and many state agencies have conducted numerous field studies for the feasibility of using recycled tire rubber products in HMA pavements. Several test cases in the US (California, Texas, Florida) have shown reductions in pavement noise when compared to conventional, without rubber, asphalt pavements. In many cases, a reduction in highway noise was evident even after widening of the roadway, resulting in higher traffic volumes and speeds [15]. In Arizona, the excellent noise-reducing properties have been highlighted and have been a major driver for replacing much of constructed concrete surfaces by rubberized asphalt bituminous ones. A type of dense asphalt with a high content of polymer-modified binder (the amount of rubber in the surface is around $1.5 \%$ by weight) has been developed and used with excellent acoustic properties.

The asphalt rubber technique has also gained interest in European countries. Portugal has extensive experience on this methodology [16]. In Sweden, at the end of 2009, about 15 test sections had been constructed using approximately 57,000 tonnes of rubberized asphalt/bitumen covering about 100 lane-km. In 1998, in Ireland, the crumb rubber modified material developed in France by Colas S.A. was laid on three sites on the public highway in order to assess its acoustic performance. The three sites analysed in this study could be classified as noisy surfaces. Resurfacing with a crumb rubber modified surface can result in large reductions in traffic noise levels of over $5 \mathrm{~dB}(\mathrm{~A})$ [17]. Table 3 lists some international projects carried out [18].

Noise readings show that rubberized asphalt generally reduces traffic noise levels by about 2 - 3 decibels and in some cases by as much as 10 decibels. This high level of reduction of noise is due to the embedding gradation of the pavement surface, namely pavement with high porosity. The open graded pavements have many air voids $(<20 \%)$ and provide noise absorption. Rubberized asphalt pavements may provide more noise absorption than conventional porous surfaces due to the resilient properties of rubber. It is possible that clogging may be a much smaller problem than in conventional porous surfaces because the dirt which accumulates will not get stuck in the porosities, since the rubber layer is all the time moving when a tire rolls over it [19].

\subsection{Procedure-Equipment Used}

In the frame of LIFE+ project with Acronym ROADTIRE, one section of road in the city Lamia, Vasilikon Street, has been selected for the pilot application of the rubberized asphalt pavement. Vasilikon Street, which is part of the National Road of Athens-Lamia-Karpenisi, is considered a street with high traffic, since many trucks are passing by. Traffic noise is one of the most serious concerns to issue related with environmental quality in the urban community. Population growth has led to increased volume of vehicles generating more highway noise.

According to the implementation of the project, pavement with the upper surface layer made of rubberized bituminous, dense graded mixture of a thickness of $0.05 \mathrm{~m}$ has been applied only to the one line of the road. The total width of the layer was approximately $5 \mathrm{~m}$ for a distance of $500 \mathrm{~m}$ (Figure 1).

Table 3. Countries used rubberized asphalt and resulting noise reduction.

\begin{tabular}{ccc}
\hline Country & Year reported & Noise level reduction \\
\hline Belgium & 1981 & $8-10 \mathrm{~dB}$ \\
France & 1984 & $2-3 \mathrm{~dB} / 3-5 \mathrm{~dB}$ \\
Germany & 1980 & $3 \mathrm{~dB}(50 \%)$ \\
Austria & 1988 & $3+\mathrm{dB}$ \\
Netherlands & 1988 & $2.5 \mathrm{~dB}$ \\
Canada & 1991 & Shown noise reduction \\
Arizona, USA & 1990 & $10 \mathrm{~dB}(88 \%)$ \\
California, USA & $1991-1993$ & $3-7 \mathrm{~dB}$ \\
\hline
\end{tabular}




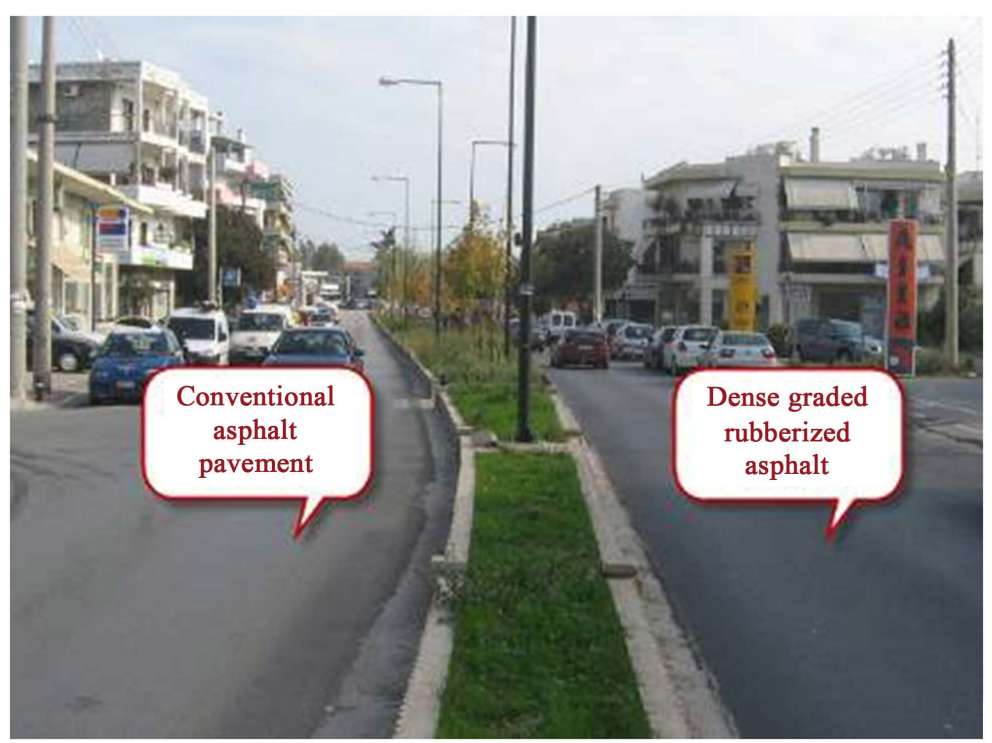

Figure 1. Pilot project of Vasilikon Street.

Street's preparation actions included the removal of old surface bituminous layer by the use of appropriate machinery and cleaning by the use of brush (Figure 2). Before laying of the new asphalt layer, tack coating took place, so as to enhance bonding between the remained old asphalt layer of the road pavement and the new one (Figure 3). Finally the pilot application was completed by compaction of the new layer with the rubberized bituminous mixture (Figure 4). All preparatory actions as well as actions during the implementation have been supervised by engineers from municipality of Lamia and engineers from Laboratory of Building Materials of AUTh.

\subsection{Procedure of Measurements}

Present paper is focused on the results and findings of traffic and noise measurements, on this road section in the city of Lamia, conducted in November 2011 and in June 2012, 8 months later. The main scope of this research was to find out if the implementation of a layer of rubberized asphalt could reduce the noise pollution that is associated with the road traffic and whether or not this reduction remains in time.

Two measurement points for Vasilikon street were selected based on their accessibility as well as on characteristics related to typical conditions primarily in the ambient noise level and road geometry. The measurement locations were selected to be as generically representative as possible, characterized by a free flow of vehicles, with constant speed, without traffic lightings nearby. The mean vehicle speed was $40 \mathrm{~km} / \mathrm{h}$, while the environmental temperature ranged between $7^{\circ} \mathrm{C}$ and $12^{\circ} \mathrm{C}$ during the measurements.

One point of the road was in the conventional asphalt pavement and the other in the rubberized one. Noise measurements were conducted, by positioning the microphone at a height of $0.30 \mathrm{~m}$, away from intersections so as to ensure accurate measurements and to enhance the pavement noise source (traffic noise is generated primarily by the interaction of the tires and the pavement (78\%), engine and exhaust noise (12\%), and aerodynamic effects $(10 \%))$.

Two Noise Level Analyzers type 2237 “Brüel \& Kjær” were used, according to recommendations of International Standard Organization for the measurement of traffic noise, for each point measurement, together with a calibrator used to guarantee measurement accuracy. The noise level meters were programmed to continuously measure the A-weighted noise level and store the energy-equivalent noise level $\left(\mathrm{L}_{\mathrm{eq}}\right)$. The acoustic survey was carried out in two consecutive working days for three different time intervals. Specifically, the first survey-time intervals were between 10:00 a.m. and 12.00, the second survey-time interval from 12:00 to 02:00 p.m. and the third survey-time interval from 06:00 p.m. to 08:00 a.m. Time interval of each measurement was 10 min, time long enough for the statistical levels to remain stable in this type of measurement and situation. The level of noise $\left(\mathrm{L}_{\mathrm{eq}}\right)$ was measured three consecutive times, for each point, of the same 10-minute period. The final value $\left(\mathrm{L}_{\mathrm{eq}}\right)$ is the average of the three 10-minute period. 


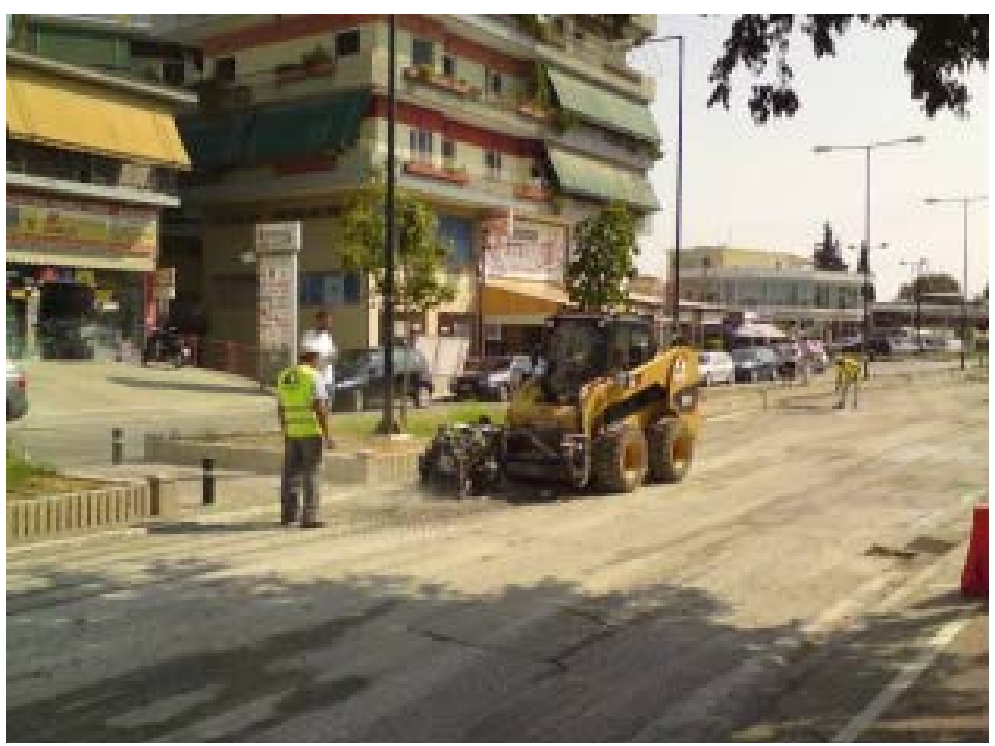

Figure 2. Removal of the old surface and cleaning at Vasilikon Street.

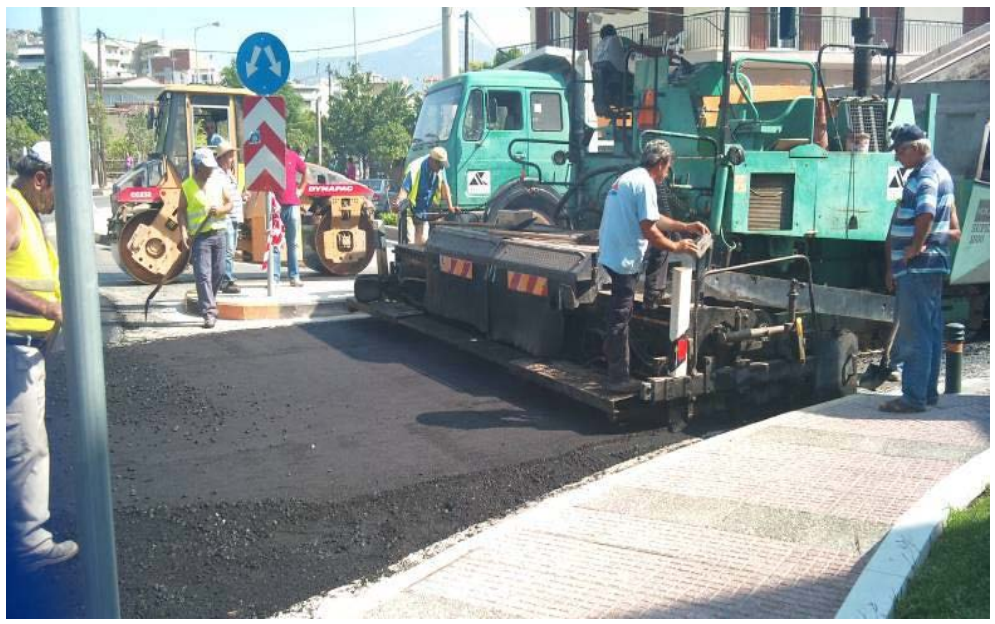

Figure 3. Laying at Vasilikon Street.

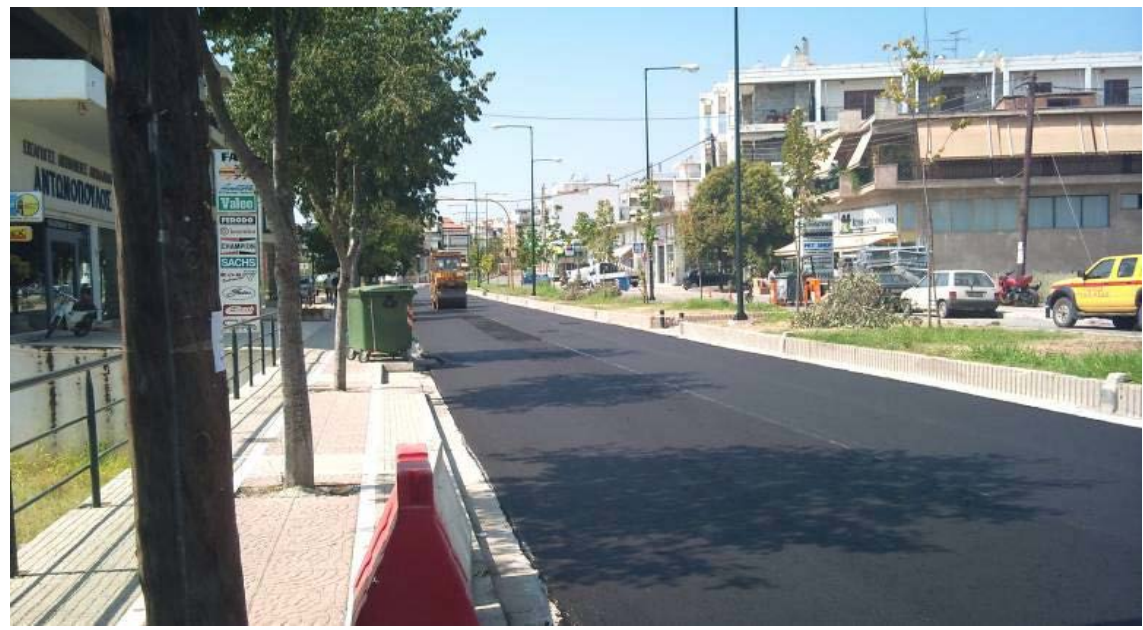

Figure 4. Compacting at Vasilikon Street. 


\subsection{Analyze Method}

Traffic monitoring was conducted by making manual vehicle counts. The traffic counts were made continuously during the 10-minute noise measurement periods at each point survey. The vehicle classification included passenger cars, heavy trucks and motorcycles. When the traffic monitoring and the corresponding level of noise of each point were conducted, the other lane of street was out of traffic. For this purpose, the help of municipal authorities and police was significant and necessary in order to obtain reliable measurements. Traffic and vehicles' distribution are presented in Table 4, where it can be noticed that Vasilikon Street is characterized by the high number of trucks and the higher speed rate, especially in the "rubberized asphalt road section".

As described above, the noise data were obtained under different traffic conditions. As shown in Table 4, the number of cars counted in the three point surveys varied; especially, number of trucks and motorcycles differed significantly. In order the measured noise levels to be correlated to an equivalent number of vehicles at each site, an Equivalent Number of Vehicles (EN) was used, so that the actual change in traffic noise level could be obtained. This Equivalent Number of Vehicles was elaborated by the Highway Laboratory of Civil Engineering of Aristotle University of Thessaloniki.

The Indicator EN expresses the equivalent number of vehicles passing by a location and produces the same level of noise $\mathrm{L}_{\mathrm{eq}}$ with the level of noise that the different categories of traffic produce. The different coefficients of the parameters were based on the European Union legislation on environmental noise and the upper limits of noise exposure of different means of transport (namely the upper limit of noise exposure of car is $74 \mathrm{~dB}$, the upper limit of truck is $80 \mathrm{~dB}$ and the upper limit of motorcycle is $77 \mathrm{~dB}$ ). Moreover, for an urban area, heavy vehicles have been assumed to generate a noise that is ten times louder than cars' one according to the European Commission. This value of EN is computed from:

$$
E N=N_{v}+3 \cdot N_{L}+10 \cdot N_{H}
$$

where: $E N=$ Equivalent Number of Vehicles;

$N_{V}=$ number of passenger cars;

$N_{L}=$ number of motorcycles;

$N_{H}=$ number of trucks.

\section{Results and Discussion}

The results of noise and traffic measurements in Vasilikon Street, for the two measurement points are summarized in Table 5 (six measurements of ( $\mathrm{L}_{\mathrm{eq}}$ ) for each point) immediately after the laying of the modified top surface layer as well as in Table 6, 8 months after its operation. The average measured sound levels obtained in each survey are compared to the corresponding equivalent number of vehicles of each time-period survey.

Figure 5 represents the combination of the equivalent number of vehicles and the corresponding traffic level of noise, during the two period of survey, after construction of the pavement and 8 months later.

Table 4. The registered traffic.

\begin{tabular}{ccc}
\hline Vasilikon Street & Traffic (v/h) & Distribution (\%) (approximately) \\
\hline Lane with conventional asphalt & $240-400$ & $82 \%$ cars \\
Lane with rubberized asphalt & $360-600$ & $10 \%$ trucks \\
\hline
\end{tabular}

Table 5. Results of noise and traffic measurements in Vasilikon Street.

\begin{tabular}{ccccc}
\hline & \multicolumn{3}{c}{ Vasilikon Street } \\
\hline & \multicolumn{3}{c}{ Site “1” with conventional asphalt pavement } & Site “2” with rubberized asphalt pavement \\
\hline Surveys & Equivalent number of vehicles & Level of noise $\mathrm{L}_{\text {eq }}(\mathrm{dB})$ & Equivalent number of vehicles & Level of noise $\mathrm{L}_{\text {eq }}(\mathrm{dB})$ \\
\hline 1 & 151 & 70.6 & 184 & 70.6 \\
2 & 123 & 71.5 & 138 & 138 \\
3 & 200 & 72.6 & 107 & 68.9 \\
4 & 126 & 69.5 & 131 & 68.1 \\
6 & 156 & 71.1 & 141 & 68.5 \\
\hline
\end{tabular}


Table 6. Results of noise and traffic measurements in Vasilikon Street, 8 months later.

\begin{tabular}{ccccc}
\hline \multicolumn{5}{c}{ Vasilikon Street } \\
\hline \multicolumn{4}{c}{ Site “1” with conventional asphalt pavement } & Site "2" with rubberized asphalt pavement \\
\hline Surveys & Equivalent number of vehicles & Level of noise $\mathrm{L}_{\text {eq }}(\mathrm{dB})$ & Equivalent number of vehicles & Level of noise $\mathrm{L}_{\text {eq }}(\mathrm{dB})$ \\
\hline 1 & 155 & 72 & 137 & 69.5 \\
2 & 83 & 72.5 & 95 & 68.9 \\
3 & 138 & 71.6 & 83 & 68.1 \\
4 & 156 & 72.8 & 124 & 70.1 \\
5 & 125 & 71.6 & 101 & 70 \\
\hline
\end{tabular}

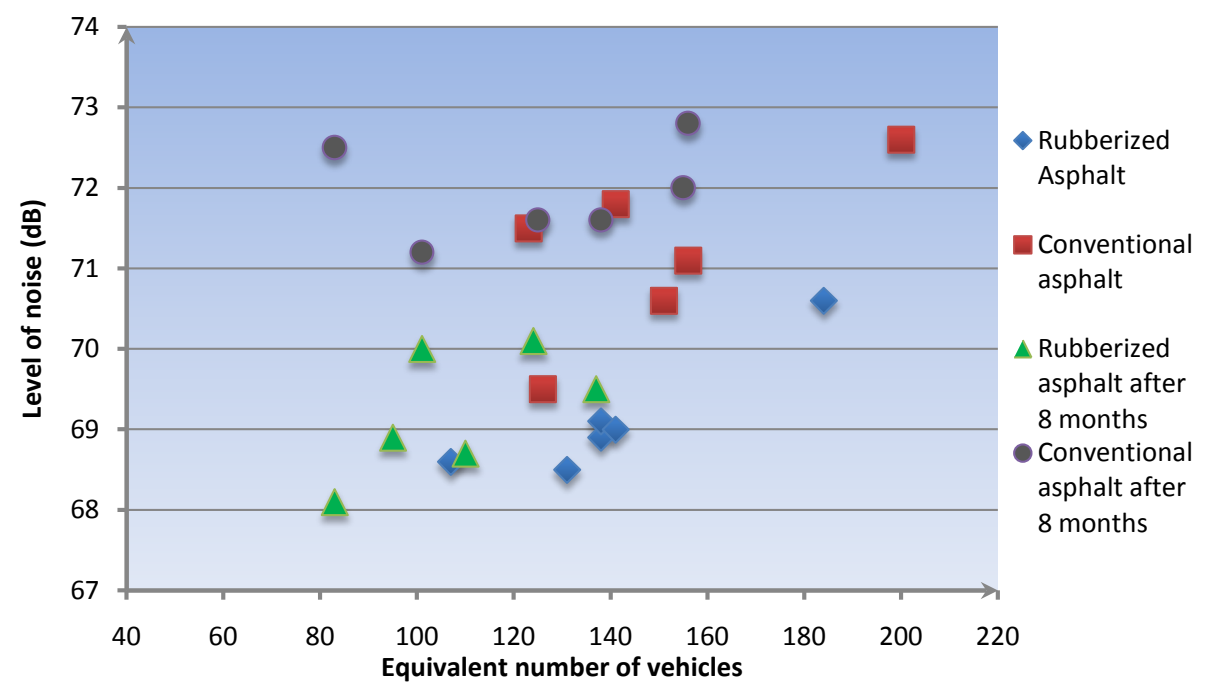

Figure 5. Combination of level of noise and the equivalent number of vehicles.

Analysis of the results shows that, generally, the rubberized asphalt pavement performs better than the conventional one as far as reduction on traffic noise level is concerned. The values of noise range from $73-71 \mathrm{~dB}$ in conventional asphalt pavement and $70-68 \mathrm{~dB}$ in rubberized asphalt pavement. The measured difference is about 1 - $3 \mathrm{~dB}$. It is remarkable that, despite the dense gradation of the pavement surface, it is obvious a reduction in noise level. Moreover, this improved performance of the rubberized asphalt pavement compared to the conventional one remained the same even 8 months after its operation. The results of noise reduction could be enhanced if open-graded rubberized bituminous mixture was implemented. However, the good noise performance of rubberized asphalt pavement has been minimized a bit, after a period of 8 months.

\section{Conclusions}

In recent years there has been a great and continuous effort to utilise EOL tires that are being stockpiled worldwide. This is primarily due to the issued legislation inside and outside the European Community, which sets quantitative targets concerning the alternative to landfilling utilization of such wastes, as well as on technological progress on EOL Tires' waste management and the realization of the associated environmental benefits. Main benefit derived from the utilization of EOL Tires in civil engineering works and especially in road construction is preservation of raw materials and efficient waste management since tire waste either replaces natural resources or it is utilized as raw material, re-entering construction's life cycle.

The main research query of present paper has been the examination of whether or not, bituminous layer made of rubberized dense-graded bituminous mixture, implemented for the first time in Greece, through a pilot appli- 
cation, produces not only a satisfactory in terms of mechanical and physical characteristics but also a "quieter" pavement. In particular, mixture implemented included $5 \%$ of rubberized bitumen, modified with a lower than the one mentioned in existing bibliography percentage of tire rubber $(10 \%<15 \%)$. This lower percentage has been chosen after extensive laboratory experimental research on bituminous binder's, aggregates' and bituminous mixtures' characteristics, which could satisfy existing Greek specifications-concerning top surface bituminous layer of pavement.

Moreover, in order the measured noise levels to be correlated to an equivalent number of vehicles at each site, an Equivalent Number of Vehicles (EN) was used, in order to obtain the actual change in traffic noise level.

Results of noise surveys conducted on the rubberized and conventional pavements, when compared, indicate that the use of rubberized bituminous mixtures can reduce traffic noise exposure levels by 1 to $3 \mathrm{~dB}$. This reduction can be attributed to rubber particles structure and characteristics, as well as in the special mixing conditions for the preparation of the modified binder, which has been followed in present paper and is unique not only for Greece but for most of the European countries as well. Moreover, when one considers that the decibel scale is logarithmic - every increase of ten decibels means a sound twice as loud as the former one-these numbers represent significant decreases on traffic noise at the pavement itself. Advantage of the use of such bituminous mixture has been also certified by citizens and especially drivers, who mentioned the better performance of the

lane, with the modified rubberised asphalt mixture as far as noise level and comfort in travelling is concerned. The results of noise reduction could be enhanced if open-graded rubberized bituminous mixture was implemented, which means by the use of other types of aggregates' gradations, natural and recycled ones (derived from Construction and Demolition Wastes-C\&D W-), leading to combined utilization of two waste streams (EOL Tires and C\&D W).

The main conclusion of present research, unique for Greece is that rubberized bituminous mixtures could be a good solution for the re-surfacing of any street which is in poor condition, since not only does it reduces noise generation, but it also provides more durable pavements that are less susceptible to the effects of temperature, while maintaining the noise reduction even after 8 months of operation. Furthermore, the inventory and mapping of road network of Greece showed that Greece has an existing and projected road network of sufficient length that may be used for the integration of a huge quantity of EOL Tires providing significant environmental benefits. Consequently, use of EOL Tires in road pavements is highly recommended to be efficiently promoted by the national legislation as well since the whole quantity of stockpiled EOL Tires could be managed in a technical and environmentally friendly way. Besides existing good practices even in USA and other European countries, enhance the utilization of EOL Tires in road construction.

\section{Acknowledgments}

This research has been realized with the contribution of the LIFE financial instrument of the European Union. Special thanks to the staffs of Municipality of Lamia and of the Laboratory of Materials Testing and Quality Control of Public Works of Sterea Ellada and especially to the Head of the Lab, Mr Kalofotia Athanasio and to the Vice-Mayor of Technical Services of Municipality of Lamia Mr. Evangeliou Pano.

\section{References}

[1] European Tire Recycling Association (ETRA) http://www.etra-eu.org/ European Commission (1996) Future Noise Policy. Green Paper, Brussels.

[2] Nehdi, M. and Khan, A. (2001) Cementitious Composites Containing Recycled Tire Rubber: An Overview of Engineering Properties and Potential Applications, Cement, Concrete and Aggregates. CCAGDP, 23. http://dx.doi.org/10.1520/CCA10519J

[3] Rafat, S. and Naik, R.T. (2004) Properties of Concrete Containing Scrap-Tire Rubber-An Overview. Waste Management, 24, 563-569. http://dx.doi.org/10.1016/j.wasman.2004.01.006

[4] Mavridou, S. (2010) Utilization of Recycled Tire Rubber in Mortars and Concrete Based on Cement or Asphalt for Special Applications. Ph.D. Thesis, Department of Civil Engineering, Aristotle University of Thessaloniki, Greece (in Greek).

[5] Khosla, N.P. and Trogdon, J.T. (1990) Use of Ground Rubber in Asphalt Paving Mixtures. Technical Report, Department of Civil Engineering, North Carolina State University, Raleigh. 
[6] Khalid, H.A. and Artamendi, I. (2002) Exploratory Study to Evaluate the Properties of Rubberized Asphalt Modified Using the Wet and Dry Processes. 3rd International Conference on Bituminous Mixtures and Pavements, J \& A Publishers, Thessaloniki, 15-25.

[7] Airey, G.D., Collop, A.C. and Mujibur, M.M. (2004) Mechanical Properties of Crumb Rubber Modified Bituminous mixtures. 3rd Eurasphalt \& Eurobitume Congress, Vienna.

[8] Oikonomou, N. and Mavridou, S. (2009) The Use of Waste Tire Rubber in Civil Engineering Works. In: Khatib, J., Eds., Sustainability of Construction Materials, Chapter 9, Woodhead Publishing, Cambridge, 213-238. http://dx.doi.org/10.1533/9781845695842.213

[9] Mavridou, S., Oikonomou, N. and Kalofotias, A. (2012) Overall Report on the Pilot Application at the End of the Project, September 2012, EU-LIFE+ Environment Policy and Governance LIFE 09 ENV/GR/304“ROADTIRE”, “Integration of End-of-Life Tires in the Life Cycle of Road Construction” ROADTIRE.

[10] EN12697-34 (2004) Bituminous Mixtures-Tests Methods for Hot Mix Asphalt-Part 34: Marshall Test.

[11] http://www.esha.gr/

[12] ПТП А265-A (1966) Bituminous Concrete, Greek Specifications.

[13] ПЕТЕП 05-03-11-04 (2006) Bituminous Layers of Closed Type. Edition 1, May 2006 (Greek Specifications).

[14] EN 12697-22 (2003) Bituminous Mixtures_-Tests Methods for Hot Mix Asphalt. Part 22: Wheel Tracking.

[15] Putman, B. and Amirkhanian, N. (2005) Rubberized Bituminous Mixtures: A Novel Approach to Pavement Noise Reduction. WIT Transactions on the Built Environment, 77.

[16] SILENCE (2005) Report of Promising New Road Surfaces for Testing.

[17] Brennan, M., Kavanagh, A. and Sheahan, J. (2001) Case Studies of a Low-Noise Road Surface. International Journal of Pavement Engineering, 2, 121-134. http://dx.doi.org/10.1080/10298430108901721

[18] Bollard \& Brennan, Inc. and Sacramento County Department of Environmental Review and Assessment (1999) Report on the Status of Rubberized Asphalt Traffic Noise reduction in Sacramento County.

[19] Sandberg, U. (1992) Do Road Surfaces with Rubber Give Noise Reduction? Engineering Foundation Conference "Vehicle-Road Interaction II", Santa Barbara. 
Scientific Research Publishing (SCIRP) is one of the largest Open Access journal publishers. It is currently publishing more than 200 open access, online, peer-reviewed journals covering a wide range of academic disciplines. SCIRP serves the worldwide academic communities and contributes to the progress and application of science with its publication.

Other selected journals from SCIRP are listed as below. Submit your manuscript to us via either submit@scirp.org or Online Submission Portal.
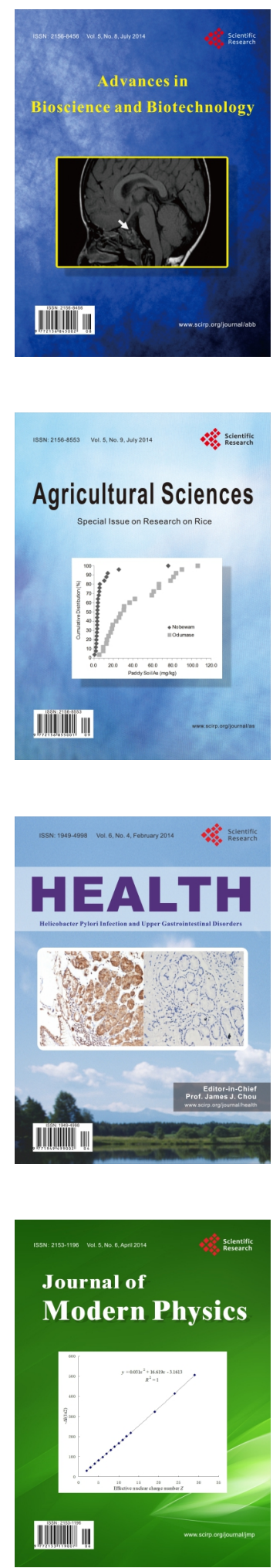
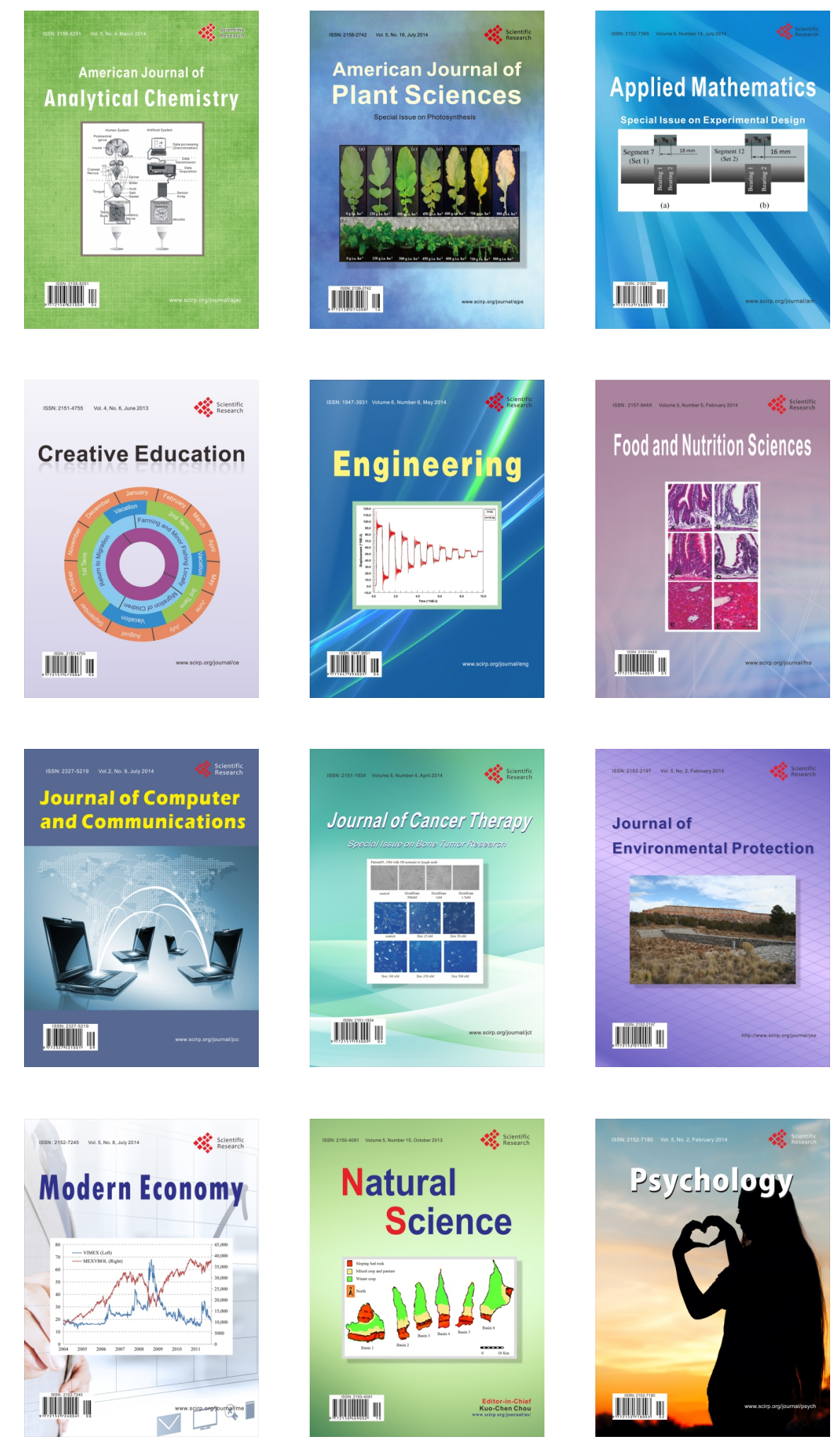